\title{
HBIM METHODOLOGIES FOR THE ARCHITECTURAL RESTORATION. THE CASE OF THE EX-CHURCH OF SAN QUIRICO ALL'OLIVO IN LUCCA, TUSCANY
}

\author{
G. Bacci $^{1}$, F. Bertolini ${ }^{1}$, M.G. Bevilacqua ${ }^{1}$, G. Caroti $^{2}$, I. Martínez-Espejo Zaragoza², M. Martino ${ }^{1}$, A. Piemonte ${ }^{2}$ * \\ ${ }^{1}$ DESTEC, University of Pisa (g.bacci@archiworld.it; f.bertolini.e@gmail.com; mg.bevilacqua@ing.unipi.it; \\ m.martino@ing.unipi.it) \\ 2 DICI, University of Pisa (gabriella.caroti;andrea.piemonte)@unipi.it
}

ISPRS WG II/8, WG III/5, WG V/1

KEY WORDS: HBIM, Structure from Motion, Scan to BIM, San Quirico all’Olivo, Lucca

\begin{abstract}
:
In the last decade, in the field of conservation of historic buildings, several research projects have shown the potential of applying BIM technology to architectural heritage. However, the use of BIM for historic buildings (HBIM) is still evolving. This paper presents an application of Building Information Modelling targeted to the development of a restauration proposal for the ex-church of San Quirico all'Olivo in Lucca, Tuscany. Following a brief review of the state-of-the-art of BIM applied to architectural heritage, the paper shows the results of a study that included 3D architectural survey with Structure-from-Motion methodology, critical analysis of historical archival and bibliographic sources, analysis of the conservation status of the building, proposal for its conservation and enhancement.

HBIM methodology has been critically applied to all the phases of the project. This study also explores the possibility of organizing the BIM model into temporal phases, integrating documentation in a structured and easily accessible way. In our study, we also chose to link the 3D point cloud to the model, in order to increase the level of information; the 3D survey, therefore, is both the starting point for modelling, and represents a source of information within the model, to be recalled when required.
\end{abstract}

\section{INTRODUCTION}

The BIM (Building Information Modelling) has gained international acclaim in the field of conservation of historic buildings information management and its representation.

In the last decade, several research projects have shown the potential of applying BIM technology to architectural heritage [Murphy et al., 2009; Logothetis et al., 2015; Megahed, 2015].

The digitalization of existing artefact with artistic and historical significance is defined as H-BIM (Historical Building Information Modeling) and is becoming a very important topic. A multidisciplinary approach that links different disciplines like geomatics, restoration, history and data collection is the best way to manage different activities and knowledge.

Since the use of BIM for historic buildings (HBIM) is evolving, the generation of complex geometries from points cloud acquisition is still an issue due to its time-consuming and complicated procedure. Indeed, non-homogeneous architectural elements which characterized historical buildings are difficult to parameterize [Baik et al., 2014; Barazzetti et al., 2015; Brumana et al., 2013; Volk et al. 2014; Oreni et al. 2017; Tang et al., 2010].

The HBIM 3D parametric model can provide geometric and alphanumeric information, that can be used to improve a building project.

The enrichment of a relational database linked to the elements of a 3D HBIM model, an alphanumeric data that can be used for managing the conservation interventions [Baik et al., 2014; Dore and Murphy, 2012; Oreni, 2013; Utica, 2017; Solihin et al. 2017].

\footnotetext{
* Corresponding author
}

\section{MATERIALS}

Development of a BIM project on Cultural Heritage objects requires, in the first place, a $3 \mathrm{D}$ survey of its status quo, allowing its virtual reconstruction at different scales, based on the required Level of Detail (LoD). The availability of texture mapping can also be required, in addition to geometry definition.

The evolution of geomatics methodologies currently provides several solutions for the generation of such models.

To date, the highest performing methodology as regards geometric precision and strictness in texture mapping is the integration between laser scanning and photogrammetry [Caroti et al., 2015; Cipriani \& Fantini, 2017; Gruen, 2009; Piemonte, et al., 2018], the latter in its latest acceptation, i.e. exploiting Structure from Motion and Multi-View Stereo algorithms [Remondino et al., 2014; Wenzel, et al., 2013].

Both survey methodologies provide high geometric resolution, which, while quite useful for appropriate shape definition, is often scaled down in the Scan-to-BIM phase, i.e. the transition from half-raw survey data (point clouds) to models, of the parametric modelling process, typical of BIM projects [Bosché et al., 2015; Chiabrando, et al. 2016].

This phase provides designing and building a parametric object library, based on data originating from either existing architecture treatises and manuals or actually collected information, such as archive data and surveys. [Dore \& Murphy, 2015]. These parametric objects, which represent single building components, will be subsequently merged into a unified virtual representation of the historic heritage building [Cipriani et al., 2014]. When modelling unique existing historic buildings, it is advisable to evaluate whether exploiting existing 
libraries or implementing new ones, especially for complex, intricate shapes [Murphy et al., 2013; Lari et al. 2011]

Methods and software allowing for automatic or semi-automatic detection of architectural elements are currently under investigation.

This particular step in data processing is critical, since it defines the geometric structure to which the database of design and status quo information is linked.

\subsection{Case study}

The methodology described in the paper has been tested on an actual case study by developing in BIM the restoration project of the disused church of San Quirico all'Olivo in the historical city center of Lucca, Tuscany, Italy.

The building currently consists of three structures: the exchurch of S. Quirico, dating back to the 13th century, and two buildings on the south side, known today as "Palazzetto di S. Quirico”.

As for the church, the building looks today very different from its original configuration. Even if it still maintains the character of a church on the outside, inside it has been heavily defaced, in particular following the transformation of the church into a cinema in the 1920s.

Recent archaeological investigations (2005) have highlighted the presence in the site of different stratifications dating back to different periods starting from the late Roman Republican Age, which confirm the historical importance of the site.

For the development of the restoration project, a careful historical-critical analysis of the bibliographic and archival sources (in the Communal Historical Archive and in the Diocesan Historical Archive of Lucca) and a stratigraphic analysis of the walls were carried out; the results allowed to identify different construction phases starting from the 14th century and to hypothesize the configuration of the church at the end of the 17th century.

The inner space of the church consists of a very bare rectangular room, about $10 \times 18.7 \mathrm{~m}$ in size. All the inner structures, dating back to the use of the church as a cinema, were in fact removed during the archaeological excavations carried out in 2005.

The basement floor preserves the archaeological remains of an ancient pavement with a portion of a mosaic dated to the Roman age, part of the stone pavement of a street of the $1^{\text {st }}$ century portions of the walls of a building dated to the 8th-9th century, and of an earlier church dated to the 10th-11th century.

\subsection{Survey methods and Scan to BIM}

This project mainly relied on a photogrammetric survey, supported by a traditional topographic survey to provide some range measures required for model scaling. The resulting point cloud entailed significantly lower costs than a laser scanning survey, while providing an adequate precision level for the 1:50 target scale.

Images have been collected with a Nikon D3100 digital camera, fitted with a 18/55mm variable lens set @18mm. CCD resolution is $4608 \times 3072 \mathrm{px}$, with a sensor size of $32.1 \times 15.4 \mathrm{~mm}$. The Ground Sampling Distance (GSD) has been set @5mm, with a $19.49 \mathrm{~m}$ maximum shooting distance. Shooting bases ranging between $4.5 \mathrm{~m}$ and $6.5 \mathrm{~m}$ allowed for $70 \%$ overlap between adjacent photograms.

Environmental conditions for the survey provided natural lighting filtering through the windows, with sharp contrasts between lit vs. shaded regions.
Therefore, images collected in RAW format were processed by filtering tonal parameters with Adobe Lightroom postproduction software. This allowed to recover information from regions which otherwise would appear either under- or overexposed.

The dense point cloud coming from image processing in Agisoft Photoscan features precision range of about $7 \mathrm{~mm}$, checked against seven scale bars uniformly laid out in the surveyed volume. This cloud has been exported in .las format, and the related textures have been exported as TIFFs.

Drafting of this project provided use of Autodesk Revit as BIM software. An intermediate step using Autodesk Recap r4.2 allowed for cloud decimation, by setting the OCTREE value @2 $\mathrm{mm}^{3}$, in order to reduce file size and subsequently optimize data management in Revit. Recap also provided for the conversion of the point cloud in .rcp format, supported by the Revit design environment.

The point cloud has subsequently been checked against the different available sources, i.e. traditional measurements, archive documents and existing 2D drawings of the status quo. Merging data from different sources has proved useful in model creation, by allowing to check the quality of heterogeneous information.

\section{METHODS AND RESULTS}

\subsection{Phases}

For the creation of the parametric model, the software chosen is Autodesk Revit. The software allows the use of temporal phases to define when an element has been created or demolished.

For this project it was possible to identify the following phases: phase 1 - Three-dimensional Survey: points cloud to be recalled when necessary;

phase 2 - Existing Building: elements belonging to the existing building to which the information about the current state of conservation is linked;

phase 3 - Restoration: elements of the existing building after completion of proposed interventions;

phase 4 - Proposals: new construction elements.

\subsection{Database}

One of the greatest advantages of BIM software is the possibility of linking information to each building component through parameters. One crucial point of the research is how to fill the model with data in a structured and easily accessible way.

Unlike with a new building project, where usually the necessary parameters are already implemented in the BIM software, on an existing building it is often necessary to add customizable attributes. These can be created within the model to include different types of information as required. In this particular project the following information has been added to the database:

- the dating of each element;

- the source of this information (archival documents, books, plans etc.);

- the location of each element;

- the type of building component according to its Uniformat II classification (ASTM E 1557-97);

- the unique identification code of each element;

- the current the state of conservation;

- the proposed conservation interventions;

- the costing of the proposed conservation measures. 


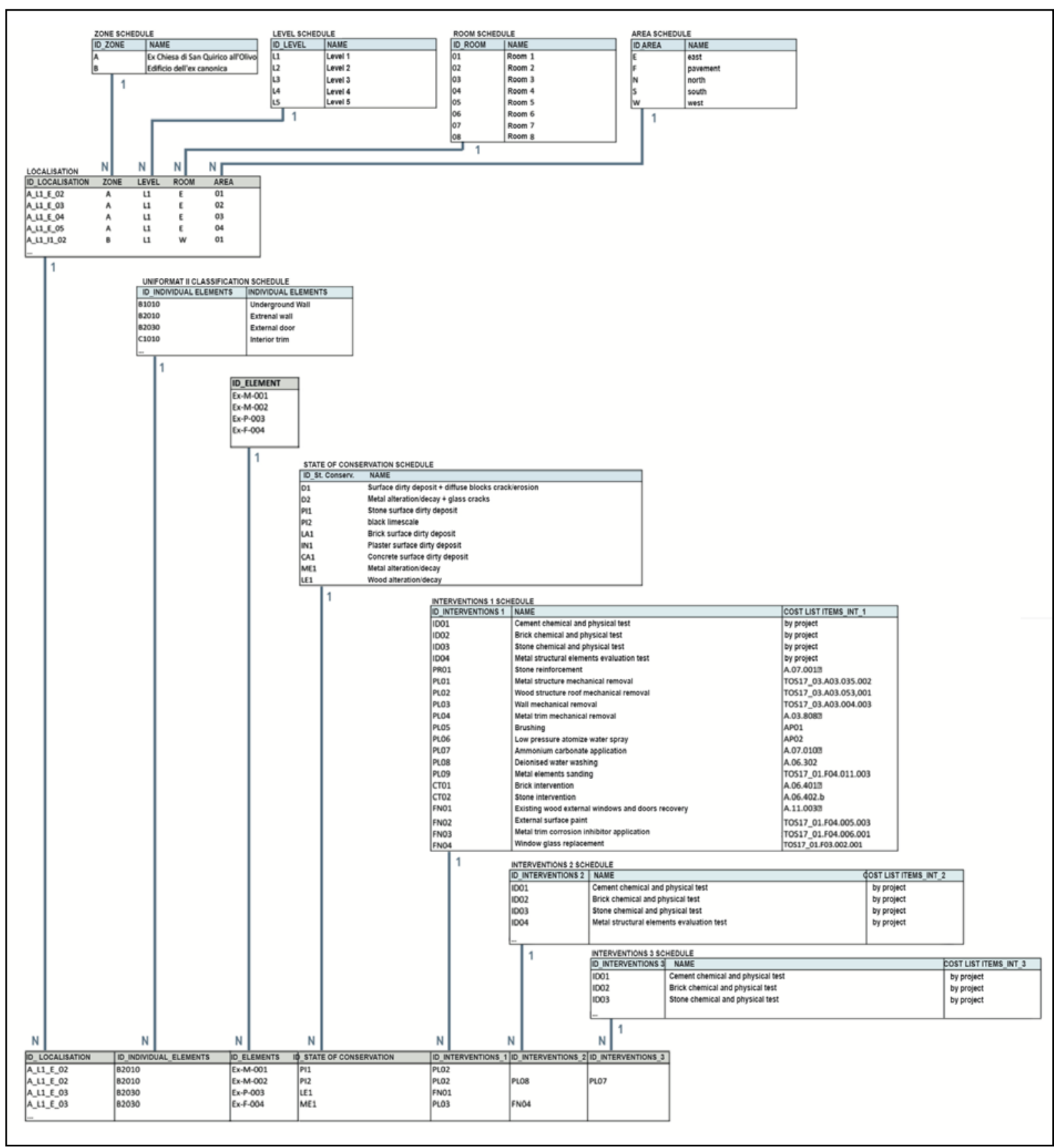

Figure 1. Relational database schema for HBIM

Following the logic of a relational database, we have summarized all the information integrated into the model, through the tables in figure 1 .

The following tools have been used in order to create ad hoc parameters in Autodesk Revit:

Project parameters: they can be included in schedules but not in labels and are specific to the project.

Shared parameters: are the most flexible and it is possible to generate project and family parameters using them. They can be shared between multiple projects and families and can be included in schedules and labels. They can also be exported via DBC or through the Revit DBLink tool. Another advantage of shared parameters is the the possibility of reusing the txt file in other similar projects, speeding up the modeling times for a future project.
The shared parameters were used for all the aspects that had to be included in schedules and in labels: location, conservation status and interventions.

Project parameters, on the other hand, have been used for those parameters that didn't have to be included into labels and when the aim was to create key schedules like the cost list items.

It is important to highlight that the parameters are related to instances, in fact not all the walls of a specific type have the same degradation.

In the Revit model the parameters become available as editable fields within the instance properties interface and allow the database enrichment (fig. 2). The creation of schedules facilitate the population of these parameter fields. In fact, given the direct connection in Autodesk Revit, every change made to the schedule is reflected in the model. 


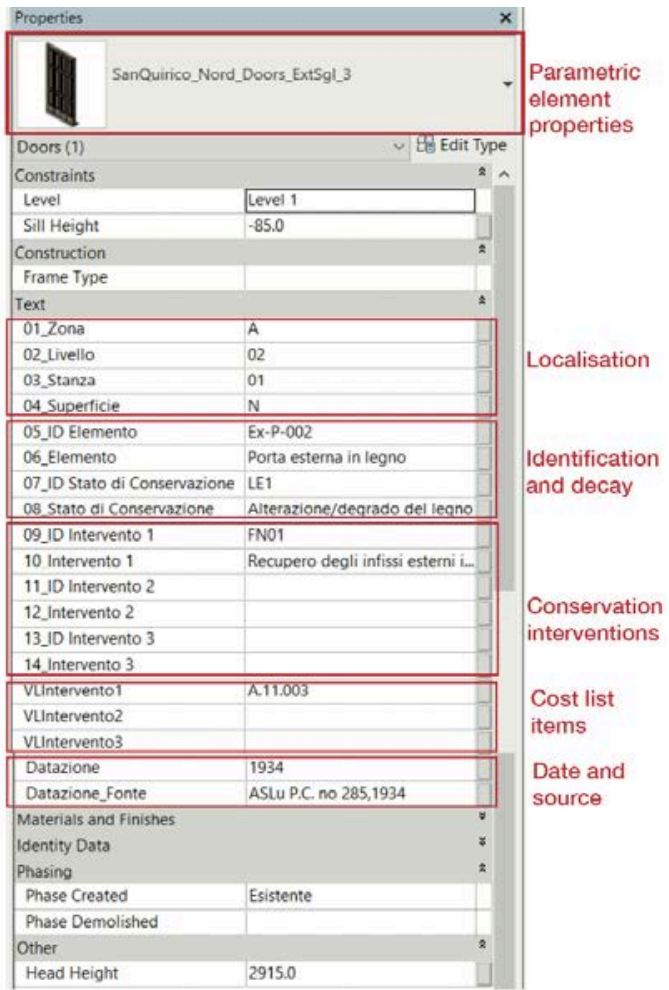

Figure 2. Shared parameters object properties

During the initial phase of database creation a way was sought to create normalized tables with relationships in Autodesk Revit. However, the software does not offer any means to do this.

One possibility is to create "key schedules", tables in which the first column is a key. However, these Revit schedules can not include shared parameters, which are the ones chosen in this case study.

It is not possible to create relationships between the normalized tables following the logic of a relational database, which would be preferable. Basically, in the project database, to each object (key) are assigned values for all the different parameter fields, which have no relation to each other.

\subsection{Generation of project documentation}

Starting from the 3D model it is possible to generate automatically the documentation of the project, 2D, 3D views, schedules and sheets.

Schedules and views are an interrogation to the model: the first ones identifies a portion of the information, selected and ordered; the second ones identify a portion of the model and represent it according to styles and customizable properties of the view itself.

Revit allows to override graphics in views using filters. This tool has been used to represent the different types of degradation creating the typical thematic views about the analysis of the conservation state. Revit allows to save these settings in specific View Templates to be recalled as required. Also, multi-category labels were used to create different type of labels that graphically represented conservation interventions (fig. 3). These are automatically updated when the parameter value changes.

Once the modelling phase is completed, it is possible to appreciate the potential of the HBIM process for the management of information on historical architectures. The use of semantically enriched 3D elements gives the possibility to browse the model, enrich it with data such as photographs, links and descriptions, 2D drawings and interrogate it, creating an unlimited number of views with the preferred visualization style, including CGI photorealistic and animation paths. This can certainly be one of the best solutions for archiving and decision making in conservation projects (fig. 4).

\subsection{Exporting}

There are many ways to export information from the BIM model. With this work we have explored three ways: Export schedules as spreadsheet to Microsoft Excel Export project data as database on Microsoft Access Export model to IFC format

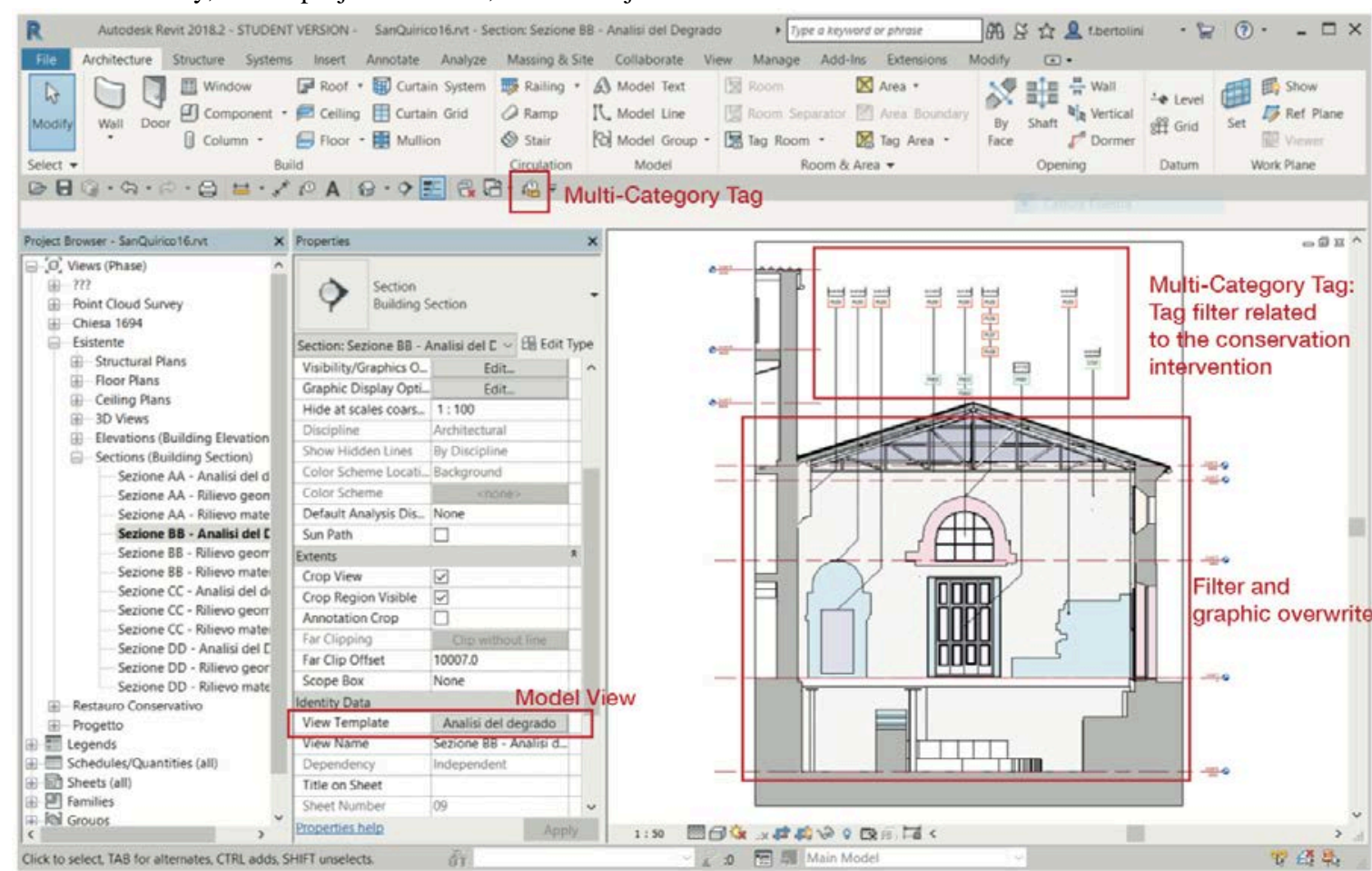

Figure 3 Multi-category tag in a model view

This contribution has been peer-reviewed. 
IFC is an exchange format that includes a classification system. In order to export from Revit there it is necessary to associate instances of Revit families with IFC categories. The assignment of the categories in Revit takes place through a dialog box in which each row represents a category or sub-category of elements.

For standard construction elements, an assigned class name is displayed in the IFC Class Name column. For building elements not automatically associated with IFC export classes, the value displayed for the IFC Class Name is "File not exported". In many cases, exporting items from Revit to an IFC file is quite simple and the default settings are appropriate. If during the creation phase of the families in Revit all the sub-categories are correctly defined, they can be mapped in the export to IFC.

An IFC Exporter from Autodesk was downloaded for IFC. The IFC2x3 Coordination View 2.0 was used, specifying the export settings, such as the phase to be exported, the project data, whether to export the whole model or just a view, to divide walls and pillars by plane, to include the outlines of a compartment, etc. The option "export schedules as a property set" allows one to define which parameters to export based on the schedules created. By activating this option all the schedules are exported. This works on all the parameters included in the schedules, whether shared or projected, and also the calculated values.

After exporting the file in IFC format from Autodesk Revit, all the exported information, including the one regarding the restoration aspects, can be easily visualized with a software as Solibri Model Viewer (fig. 5).

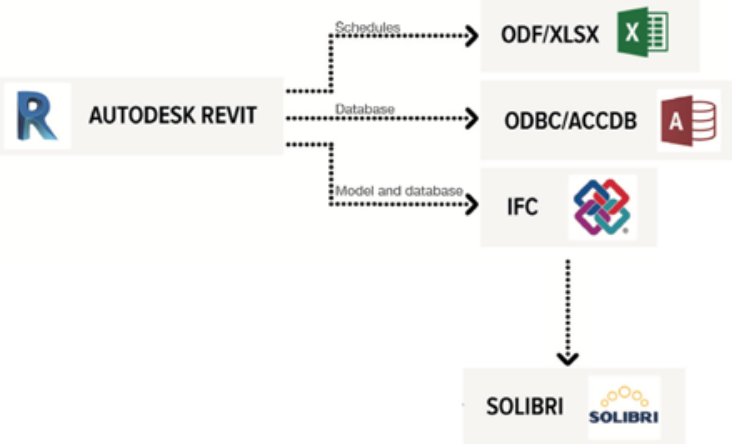

Figure 5. HBIM workflow

\section{CONCLUSIONS AND FUTURE WORKS}

The aim of this study it was to apply a procedure for modeling a cultural heritage building with the methodology of HBIM, integrating different $3 \mathrm{D}$ acquisition techniques in order to obtain an accurate 3Dmodel.

An important issue was found modeling elements. The BIM software are more used for new buildings due to a standardized procedures and parametric objects enhance the designing process. The complexity of the archeological and cultural heritage context clash with the BIM benefit. In our case of study, therefore, it was necessary to realize many ad-hoc elements, with the creation of specific local families. When creating the 3D parametric objects it was important to refer to the level of development of the model, established in accordance with the restoration purposes.

The implementation of a relational database was used to give all information related to the heterogeneous objects of the HBIM model. The way to insert and recall all this semantic information linked to the model was the main issue of this study.

This research focuses on defining a schema relational database and to bring HBIM data into a form that is easily queried. The schema is defined using relational database structure following an established hierarchical to down schema to include different types of information as required. In this particular project has been added the dating of each element, the location of each element, the type of building component according to its Uniformat II classification (ASTM E 1557-97), the current the state of conservation and the proposed conservation interventions, the costing of the proposed conservation measures.

All this information were inserted in the model by using the shared parameters of the software Revit, containers for data that needs to be made accessible and shareable among multiple families and projects.

The IFC export procedure was implemented and set in order to share all the parameters included in the schedules, whether shared or projected, and also the calculated values.

\section{ACKNOWLEDGEMENTS (OPTIONAL)}

The research was developed within the project "PRA_2017_60" financed by the University of Pisa.

\section{REFERENCES}

Baik, A., Alitany, A., Boehm, J., Robson, S., 2014. Jeddah Historical Building Information Modelling "JHBIM" Object Library. ISPRS Ann. Photogramm. Remote Sens. Spat. Inf. Sci., II-5, 2014 ISPRS Tech. Comm. V Symp. 23 - 25 June 2014, Riva del Garda, Italy II-5, 41-47. doi.org/10.5194/isprsannalsII-5-41-2014

Barazzetti, L., Banfi, F., Brumana, R., Gusmeroli, G., Previtali, M., Schiantarelli, G., 2015. Cloud-to-BIM-to-FEM: Structural simulation with accurate historic BIM from laser scans. Simul. Model. Pract. Theory 57, 71-87. doi.org/10.1016/j.simpat.2015.06.004

Bosché, F., Ahmed, M., Turkan, Y., Haas, C., Haas, R., 2015. The value of integrating Scan-to-BIM and Scan-vs-BIM techniques for construction monitoring using laser scanning and BIM: The case of cylindrical MEP components. Automation in Construction, 49 (Part B), 201-213. doi.org/10.1016/j.autcon.2014.05.014.

Brumana, R., Oreni, D., Raimondi, A., Georgopoulos, A., Bregianni, A., 2013. From survey to HBIM for documentation, dissemination and management of built heritage: The case study of St. Maria in Scaria d'Intelvi, in: Proceedings of the Digital Heritage 2013 - Federating the 19th Int'l VSMM, 10th Eurographics GCH, and 2nd UNESCO Memory of the World Conferences, Plus Special Sessions from CAA, Arqueologica 2.0 et Al. IEEE, 497-504. doi.org/10.1109/DigitalHeritage.2013.6743789.

Caroti, G., Martínez-Espejo Zaragoza, I., Piemonte, A., 2015. Range and image based modelling: A way for frescoed vault texturing optimization. ISPRS Int. Arch. Photogramm. Remote Sens. Spat. Inf. Sci., XL-5/W4, 285-290. doi.org/10.5194/isprsarchives-XL-5-W4-285-2015. 
Chiabrando, F., Sammartano, G., Spanò, A., 2016. Historical building models and their handling via 3D survey: from points clouds to user-oriented HBIM. Int. Arch. Photogramm. Remote Sens. Spatial Inf. Sci., XLI-B5, 633-640. doi.org/10.5194/isprsarchives-XLI-B5-633-2016.

Cipriani, L., Fantini, F., Bertacchi, S., 2014. 3D models mapping optimization through an integrated parameterization approach: cases studies from Ravenna. Int. Arch. Photogramm. Remote Sens. Spatial Inf. Sci., XL-5, 173-180. doi.org/10.5194/isprsarchives-XL-5-173-2014.

Cipriani, L. and Fantini, F., 2017. Digitalization culture vs archaeological visualization: Integration of pipelines and open issues. Int. Arch. Photogramm. Remote Sens. Spatial Inf. Sci., XLII-2/W3, 195-202. doi.org/10.5194/isprs-archives-XLII-2W3-195-2017.

Dore, C., Murphy, M., 2012. Integration of Historic Building Information Modeling (HBIM) and 3D GIS for recording and managing cultural heritage sites, in: 2012 18th International Conference on Virtual Systems and Multimedia. IEEE, pp. 369- 376. doi.org/10.1109/VSMM.2012.6365947

Dore C., Murphy M., 2015. Historic Building Information Modelling (HBIM), in S. Brusaporci (ed.), Handbook of Research on Emerging Digital Tools for Architectural Surveying, Modeling, and Representation, vol. I, Hershey, PA: IGI Global, 239-280.

GRUEN, A., 2009. Virtual Archaeology - New Methods of Image-Based 3D Modeling. In Reindel, M., Wagner, G. A. (Eds.) New Technologies for Archaeology. Multidisciplinary investigations in Palpa and Nasca, Peru. Springer. doi.org/10.1007/978-3-540-87438-6_17

Lari, Z., Habib, A., Kwak, E., 2011. An adaptive approach for segmentation of 3D laser point cloud. ISPRS Int. Arch. Photogramm. Remote Sens. Spat. Inf. Sci., XXXVIII-5, 103108.

Logothetis, S., Delinasiou, A., and Stylianidis, E., 2015. Building Information Modelling for Cultural Heritage: A review, Int. Arch. Photogramm. Remote Sens. Spatial Inf. Sci., II-5/W3, 177- 183.

Megahed, N. A., 2015. Towards a theoretical framework for HBIM approach in historic preservation and management. Archnet-IJAR, Int. J. Architectural Research, Vol.9/Issue3, pp.130-147.

Murphy, M., McGovern, E., Pavia, S., 2009. Historic building information modelling (HBIM). Struct. Surv., 27, pp. 311-327. doi.org/10.1108/02630800910985108

Murphy, M., Mcgovern, E., Pavia, S., 2013. Historic Building Information Modeling - Adding intelligence to laser and image based surveys of European classical architecture. ISPRS J. Photogramm. Remote Sens., 76, 89-102.

Oreni D., Brumana, R., Georgopoulos, A., Cuca, B., 2013. HBIM for conservation and management of built heritage: Towards a library of vaults and wooden bean floors. ISPRS Ann. Photogramm. Remote Sens. Spatial Inf. Sci., II(5/W1), 4954.
Oreni, D., Karimi G., Barazzetti L., 2017. Applying BIM to built heritage with complex shapes: the ice house of Filarete's ospedale maggiore in Milan, Italy. Int. Arch. Photogramm. Remote Sens. Spat. Inf. Sci., XLII-2/W5.

Piemonte, A., Caroti, G., Martínez-Espejo Zaragoza, I., Fantini, F., Cipriani, L., 2018. A Methodology for Planar Representation of Frescoed Oval Domes: Formulation and Testing on Pisa Cathedral. ISPRS Int. J. Geo-Inf., 7, 318, 1 21.

Remondino, F., Spera, M.G., Nocerino, E., Menna, F., Nex, F., 2014. State of the art in high density image matching. Photogramm. Rec., 29, 144-166.

Solihin W., Eastman C., Lee Y.-C., 2017. Multiple representation approach to achieve high-performance spatial queries of 3D BIM data using a relational database. Autom. Constr. 81, 369-388, doi.org/10.1016/j.autcon.2017.03. 014.

Tang, P., Huber, D., Akinci, B., Lipman, R., Lytle, A., 2010. Automatic reconstruction of as-built building information models from laser-scanned point clouds: A review of related techniques. Autom. Constr., 19, pp. 829-843. doi.org/10.1016/j.autcon.2010.06.007

Utica, G., Pinti, L., Guzzoni, L., Bonelli, S., Brizzolari, A., 2017. Integrating laser scanner and BIM for conservation and reuse: "the lyric theatre of Milan" ISPRS Ann. Photogramm. Remote Sens. Spatial Inf. Sci., IV-5/W1, 77-82, https://doi.org/10.5194/isprs-annals-IV-5-W1-77-2017.

Volk, R., Stengel, J., Schultmann, F., 2014. Building Information Modelling (BIM) for existing buildings Literature review and future needs. Autom. Constr. 38, 109127. doi.org/10.1016/j.autcon.2013.10.023

Wenzel, K., Rothermel, M., Fritsch, D., Haala, N., 2013. Image acquisition and model selection for multi-view stereo. Int. Arch. Photogramm. Remote Sens. Spatial Inf. Sci, XL-5/W1, 3DARCH 2013 - 3D Virtual Reconstruction and Visualization of Complex Architectures, 25 - 26 February 2013, Trento, Italy, 251-258. doi.org/10.5194/isprsarchives-XL-5-W1-251-2013

\section{Other Literature}

UNIFORMAT II, Elemental Classification for Building Specifications, Cost Estimating, and Cost Analysis. 